\title{
RESENHA
}

PSICOPOLÍTICA: O NEOLIBERALISMO E AS NOVAS

TÉCNICAS DE PODER, DE BYUNG-CHUL HAN*

Fabio Medina ${ }^{1}$

\section{TRABALHO, CONTROLE PSICOLÓGICO E CONCEPÇÕES DE LIBERDADE}

O livro que se apresenta chama-se, originalmente, Psychopolitik: Neoliberalismus und die neuen Machttechniken, foi escrito em alemão e sua primeira edição foi publicada pela Fischer Verlag Frankfurt, em 2014. A obra já foi traduzida para muitos idiomas, como inglês, espanhol, francês e italiano. O livro chega ao público brasileiro, em 2018, pela editora Ayine, intitulado Psicopolítica - o neoliberalismo e as novas formas de poder, com a tradução de Maurício Liesen. O autor é Byung-Chul Han, filósofo sul-coreano e professor da Universidade de Artes de Berlim. As suas contribuições em diversas áreas do conhecimento discutem muitos temas como sociedade do trabalho, subjetividade e dataísmo ${ }^{2}$.

Han vem sendo conhecido pelo grande público brasileiro, sobretudo por Sociedade do Cansaço (2015). Nesse trabalho, ele caracterizou a sociedade disciplinar, como descrita por Michel Foucault, como marcada pela negatividade, ou seja, por uma série de proibições de condutas e coações. Mais adiante, argumentou que, na atualidade, já não podemos falar mais em uma sociedade disciplinar, mas em uma sociedade do desempenho. Nela, os sujeitos são instados o tempo todo a ter iniciativa, motivação,

\footnotetext{
* HAN, Byung-Chul. Psicopolítica: o neoliberalismo e as novas técnicas de poder. Belo Horizonte: Editora Âyiné, 2018.

${ }^{1}$ Doutor em Antropologia pelo Programa de Pós-Graduação em Antropologia (PPGA), da Universidade Federal Fluminense (UFF). Mestre em Direito pelo Programa de Pós-Graduação em Direito Constitucional (PPGDC), também da Universidade Federal Fluminense (UFF). Pesquisador do Instituto Nacional de Ciência e Tecnologia - Instituto de Estudos Comparados em Administração Institucional de Conflitos (INCT-InEAC) e do Laboratório de Estudos Empíricos em Segurança Pública (LAESP). Atualmente, professor substituto de Direito na Universidade do Estado do Mato Grosso (UNEMAT).

${ }^{2}$ O termo refere-se a uma constante e elevada construção de dados através do que se chama de Big Data, como veremos a diante.
} 
serem rápidos e produtivos. E todo esse excesso de pressão por desempenho gera cansaço, esgotamento e adoecimento. O indivíduo é a todo tempo estimulado a ser o explorador de si mesmo ${ }^{3}$. E, com a adoção de um padrão altíssimo de exigência, e, portanto, muitos fracassos, as pessoas se sentem culpadas e envergonhadas.

Em Psicopolítica - o neoliberalismo e as novas formas de poder (HAN, 2018) o autor decide repensar algumas categorias, dentre elas, neoliberalismo e biopolítica. A primeira delas remete a uma doutrina econômica desenvolvida no final do século passado, pregando uma maior liberdade econômica e menor regulação estatal. David Harvey (1992, 2005), por exemplo, vai explicar como essa ideia se transpôs da economia política para se transformar num meio de concepção da vida na contemporaneidade. Assim, diversos teóricos vêm postulando o neoliberalismo não como uma categoria acusatória, mas como uma forma muito distinta de ser no mundo.

Já o seu debate sobre a biopolítica traça diálogos principalmente com Michel Foucault e de Giorgio Agamben. Han não pretende apontar um erro nessa conceituação, mas propõe que ele é deficiente para pensar o novo modelo neoliberal. O controle como proposto nas ideias sobre biopolítica é externo, como poder sobre a vida, ou seja, uma capacidade de administrá-la, conformando-a com o afã de produtividade típico da Idade Moderna. Era necessária uma capacidade de gestão do corpo social, visando aumentar, multiplicar, exercendo diversos controles muito precisos e regulações gerais sobre a vida. $\mathrm{E}$ esse tipo de poder estava centrado em locais de imposições de disciplina, como a escola e a fábrica, no intento de criação de corpos docilizados (FOUCAULT, 1996, 2014).

Nesse sentido, Paul Rabinow e Nikolas Rose (2006, p. 24) afirmaram,

E, enquanto Foucault é de algum modo impreciso em seu uso dos termos no campo do biopoder, podemos usar o termo 'biopolítica' para abarcar todas as estratégias específicas e contestações sobre as problematizações da vitalidade humana coletiva, morbidade e mortalidade, sobre as formas de conhecimento, regimes de autoridade e práticas de intervenção que são desejáveis, legítimas e eficazes.

O livro Psicopolítica - o neoliberalismo e as novas formas de poder (HAN, 2018) divide-se em treze partes, todas elas se comunicando fortemente com a primeira sessão,

\footnotetext{
${ }^{3}$ Tema que veremos melhor adiante.
} 
chamada de "Crise da liberdade". Nela, Han constrói um debate original sobre a noção de liberdade. "Vivemos em um momento histórico particular, no qual a própria liberdade provoca coerções" (HAN, 2018, p. 9). Han busca Hegel para definir a liberdade como a capacidade de se realizar em conjunto, em comunidade. Ele demonstra, dessa forma, como a ideia do sujeito neoliberal é paradoxal. O trabalhador se transforma em empreendedor, típica figura do neoliberalismo, e passa a se compreender como livre, mas não passa de alguém que "explora a si mesmo para a sua própria empresa" (HAN, 2018, p. 14).

Sem refletir sobre a "ditadura do capital" (HAN, 2018, p. 15), ele "considera a si mesmo como responsável e se envergonha por isso" (HAN, 2018, p. 16), por isso tantas s e enfermidades como depressão ou síndrome de burnot. Essa concepção de liberdade, contraditoriamente, não é uma oposição à coerção, portanto. Passam a existir, desse modo, "senhor e escravo" (HAN, 2018, p. 14) na mesma pessoa. Trata-se aqui de uma forma de exercício do poder mais efetiva do que o próprio panoptismo. No neoliberalismo, são os internos que se expõem, construindo de forma ativa esses mesmos panópticos. A transparência é reivindicada como um valor, e, em nome de informar, o Big Brother ${ }^{4}$ repassa a responsabilidade de construir esse panóptico aos internos.

A segunda divisão do livro é denominada de "Poder inteligente", nele o argumento é de que o poder, para além de valer-se de uma expressão de violência, pode usar do ideário de liberdade. O poder, para o autor, pode ser exercido também prolongando sua própria vontade na de outros. Trata-se de um tipo de dominação que não precisa superar resistências. Depois, em mais uma parte do texto, chamada de "A topeira e a serpente", ele traça uma metáfora distinguindo atitudes típicas da sociedade disciplinar (topeira) e da neoliberal (serpente). O individuo moderno, tal qual uma topeira, transporta-se de um meio de confinamento ao outro, confiando-se na prisão, na escola ou na fábrica. Enquanto isso, o empreendedor neoliberal, metaforizado numa serpente, é capaz de cavar seu próprio caminho, criando seus espaços. A psicopolítica, usando de discursos sobre

\footnotetext{
${ }^{4}$ Trata-se aqui de uma referência ao livro 1984, de George Orwell (2009). O Big Brother é um personagem onipresente, mas nunca visto, representa o controle do partido sobre a atitude dos cidadãos.
} 
projetos, motivações e otimizações, domina utilizando a subjetividade, essa é a forma de governar do neoliberalismo.

Nos capítulos seguintes denominados "Biopolítica" e "O dilema de Foucault", Han explica que a "técnica ortopédica" da biopolítica é por demais grosseira, e não penetra nas camadas mais profundas da psiquê. Então, ele vai elucidando como a psicopolitica, se valendo da ideia de liberdade, foi capaz de explorar até mesmo o nosso inconsciente. "O disciplinamento corporal dá lugar à otimização mental" (HAN, 2018, p. 40). Nas sessões "A cura como assassinato" e "Choque", o autor argumenta que ao invés de punições como forma de expansão da produtividade, a psicopolítica prefere trabalhar com a ideia de uma permanente, inculcando na mente dos indivíduos a necessidade de agradar a todos, causando uma série de esgotamentos e doenças mentais.

Nas três próximas partes, "O amigável grande irmão", "O capitalismo da emoção" e "Gamificação", Han expõe, com mais detalhes, como o uso de certa concepção sobre liberdade criou um nome estilo de dominação, no qual cada um é "um panóptico de si" (HAN, 2018, p. 58). As tecnologias da informação, cotidianamente, impulsionam à comunicação e ao consumo, transformando esse novo Grande Irmão um "rosto amável" (HAN, 2018, p. 57). Assim, a gratificação pelos amigos e número de seguidores nas redes sociais impulsiona toda uma valorização das emoções, uma vez que a própria psicopolítica necessita atuar num plano pré-reflexivo.

Por fins, as sessões "O big data", "Para além do sujeito" e "Idiotismo" exploram mais detidamente a ideia de dataísmo. Esse último conceito refere-se a uma capacidade tecnológica de reunir uma grande quantidade de dados, gerando a suposição de sua neutralidade ideológica. O imperativo da contemporaneidade é de que "tudo deve virar informação" (HAN, 2018, p. 80), ignorando a necessidade da percepção de que isso pode se converter em servidão. Para além de uma simples monetarização desses dados, o dataísmo expressa-se também entende "padrões coletivos de comportamento dos quais não seríamos conscientes como indivíduos" (HAN, 2018, p. 89). Assim,

O sujeito contemporâneo é um explorador de si mesmo que se autoexplora. Ao mesmo tempo é um fiscalizador de si próprio. O sujeito autoexplorador traz consigo um campo de trabalhos forçados, no qual é, ao mesmo tempo, carrasco e vítima. Como sujeito que expõe e supervisiona a si próprio, ele carrega consigo 
um pan-óptico no qual é, de uma vez só, o guarda e o interno. O sujeito digitalizado e conectado é um pan-óptico de si mesmo. Dessa maneira, o monitoramento é delegado a todos os indivíduos (HAN, 2018, p. 85).

Trata-se de uma produção extremamente atual e que se comunica com diversas áreas do conhecimento, como a Sociologia do Direito, Sociologia do Trabalho, Antropologia Social e Direito. Os seus debates sobre as ideias liberdade dos exploradores de si mesmo dialoga como um conceito importante de Ricardo Antunes (2020), os empreendedores de si mesmo. Além de ser fundamental para compreensão dos debates atuais sobre uberização (SLEE, 2018).

Por fim, o livro apresentado nos ajuda a levantar questões sobre essa crescente produção de dados. Também pode ser útil para questionar essa sociedade do controle dito psicológico, que não se impõe pelas proibições ou pelos silêncios, antes prefere que contemos, detalhadamente, todo o nosso cotidiano nas redes sócias. 0 neoliberalismo teve que criar outra narrativa sobre liberdade para desenvolver uma individualidade sempre da por não ser o escravo que poderia ser de si mesmo.

\section{REFERÊNCIAS}

ANTUNES, Ricardo. Coronavírus: $O$ trabalho sob fogo cruzado. São Paulo: Boitempo Editorial, 2020.

FOUCAULT, Michel. Vigiar e Punir: Nascimento da prisão, Petrópolis: Vozes, 1996.

FOUCAULT, Michel. História da sexualidade: $O$ uso dos prazeres (Vol. 2). São Paulo: Paz e Terra, 2014.

HARVEY, David. Condição pós-moderna. São Paulo: Loyola, 1992.

HARVEY, David. O neoliberalismo. História e implicações. São Paulo: Loyola, 2005.

HAN, Byung-Chul. Sociedade do cansaço. Petrópolis: Vozes Limitada, 2015.

HAN, Byung-Chul. Psicopolítica: o neoliberalismo e as novas técnicas de poder. Belo Horizonte: Editora Âyiné, 2018.

ORWELL, George. 1984. São Paulo: Companhia das Letras, 2009. 
RABINOW, Paul; ROSE, Nikolas. O conceito de biopoder hoje. Política \& trabalho, v. 24, p. 27-57, 2006.

SLEE, Tom. Uberização. A Nova Onda do Trabalho Precarizado. São Paulo: Elefante, 2018.

MEDINA, Fabio. Trabalho, controle psicológico e concepções de liberdade. Resenha de: HAN, Byung-Chul. Psicopolítica: o neoliberalismo e as novas técnicas de poder. Belo Horizonte: Editora Âyiné, 2018. RBSD Revista Brasileira de Sociologia do Direito, v. 8, n. 3, p. 361-366, set./dez. 2021.

Recebido em: 30/10/2020

Aprovado em: 31/05/2021 